\title{
Evaluation of two strategies to implement physical cancer rehabilitation guidelines for survivors of abdominopelvic cavity tumors: a controlled before-and-after study
}

\author{
Charlotte IJsbrandy ${ }^{1,2,3}$ - Petronella B. Ottevanger ${ }^{2}$ - Winald R. Gerritsen ${ }^{2}$ - Wim H. van Harten ${ }^{4,5}$. \\ Rosella P. M. G. Hermens ${ }^{1}$
}

Received: 19 November 2020 / Accepted: 16 April 2021 / Published online: 14 September 2021

(C) The Author(s) 2021

\begin{abstract}
Purpose This study evaluates the effectiveness and feasibility of two strategies to implement physical cancer rehabilitation (PCR) guidelines for patients who have survived abdominopelvic cavity malignancies.

Methods We tested and compared two tailored strategies to implement PCR guidelines for survivors of gastrointestinal, female organ and urogenital organ malignancies, in a clustered controlled before-and-after study. A patient-directed (PD) strategy was tested in five cancer centers, aiming to empower survivors. A multifaceted (MF) strategy was tested in four cancer centers, aiming additionally to influence healthcare professionals and the healthcare organization. Data were collected from existing registration systems, patient questionnaires and professional questionnaires. We measured both implementation- and client outcomes. For insight into the effectiveness we measured indicators related to PCR guidelines: (1) screening with the Distress Thermometer (DT) (=primary outcome measure), (2) information provision concerning physical activity (PA) and physical cancer rehabilitation programs (PCRPs), (3) advice to take part in PA and PCRPs, (4) referral to PCRPs, (5) participation in PCRPs, (6) PA uptake (PAU); and patient reported outcomes (PROs) such as (7) quality of life, (8) fatigue, and (9) empowerment. Furthermore, survivor and center determinants were assessed as possible confounders. Multilevel analyses were performed to compare the scores of the indicators of the PD and MF strategies, as well as the differences between the characteristics of these groups. The use of and experiences with both strategies were measured using questionnaires and Google Analytics to assess feasibility.

Results In total, 1326 survivors participated in the study, 673 in the before- and 653 in the after-measurement. Regarding our primary outcome measure, we found a significant improvement of screening with the DT between the before- and aftermeasurement for both strategies, respectively from 34.2 to $43.1 \%$ (delta $=8.9 \%$; odds ratio $(\mathrm{OR})=1.6706 ; p=0.0072$ ) for the PD strategy and from 41.5 to $56.1 \%$ (delta $=14.6 \%$; OR=1.7098; $p=0.0028$ ) for the MF strategy. For both the primary and secondary outcomes, no statistically significant effect of the MF strategy compared to the PD strategy was observed. We found good use of and positive experiences with both strategies.
\end{abstract}

Charlotte IJsbrandy

Charlotte.IJsbrandy@Radboudumc.nl

Petronella B. Ottevanger

Nelleke.Ottevanger@Radboudumc.nl

Winald R. Gerritsen

Winald.Gerritsen@Radboudumc.nl

Wim H. van Harten

W.v.Harten@NKI.nl

Rosella P. M. G. Hermens

Rosella.Hermens@Radboudumc.nl
1 Scientific Institute for Quality of Healthcare (IQ healthcare), Radboud Institute for Health Science (RIHS), Radboud University Medical Center Nijmegen, PO Box 9101, 6500, HB Nijmegen, the Netherlands

2 Department of Medical Oncology, Radboud Institute for Health Science (RIHS), Radboud University Medical Center Nijmegen, Nijmegen, the Netherlands

3 Department of Radiation Oncology, Radboud Institute for Health Science (RIHS), Radboud University Medical Center, Nijmegen, the Netherlands

4 Division of Psychosocial Research and Epidemiology, Netherlands Cancer Institute, Amsterdam, the Netherlands

5 Department of Health Technology and Services Research, MB-HTSR, University of Twente, Enschede, the Netherlands 
Conclusion Implementation strategies containing tools enhancing patient empowerment seem to be effective in increasing the systematic screening with the DT for survivors of abdominopelvic cavity malignancies. Further research is needed to assess the additional effectiveness of strategies that stimulate compliance among healthcare professionals and healthcare organizations. Implications for Cancer Survivors Using implementation strategies containing tools enhancing patient empowerment seem to be effective in increasing the systematic screening with the DT and might improve the quality of care of patients who have survived abdominopelvic cavity malignancies.

Keywords Exercise $\cdot$ Health plan implementation $\cdot$ Guidelines $\cdot$ Neoplasm $\cdot$ Rehabilitation $\cdot$ Survivors

\section{Abbreviations}

EORTC QLQ-C30 The European Organization for Research and Treatment of Cancer Quality of Life Questionnaire

$\begin{array}{ll}\text { GP } & \text { General practitioner } \\ \text { ICC } & \text { Intraclass coefficient } \\ \text { No } & \text { Number of } \\ \text { MF strategy } & \text { Multifaceted strategy } \\ \text { MFI-20 } & \text { Multidimensional Fatigue Inventory-20 } \\ \text { OR } & \text { Odds ratio } \\ p & p \text { value } \\ \text { PA } & \text { Physical activity } \\ \text { PAM-13 } & \text { Patient Activity Measurement-13 } \\ \text { PAU } & \text { Physical activity uptake } \\ \text { PCR } & \text { Physical cancer rehabilitation } \\ \text { PCR guideline } & \text { Physical cancer rehabilitation guideline } \\ \text { PCRP } & \text { Physical cancer rehabilitation program } \\ \text { PD strategy } & \text { Patient-directed strategy } \\ \text { QoL } & \text { Quality of life }\end{array}$

\section{Introduction}

Maintaining a physically active lifestyle during and after cancer is advisable to counteract symptoms related to cancer and its treatment [1-23], although it is challenging for patients $[24,25]$. After cancer has been diagnosed, physical activity (PA) levels often deteriorate distinctly [26], with only a low proportion of patients with cancer showing sufficient PA during treatment [27, 28]. Additionally, survivors of cancer fail to return to prediagnosis PA levels after treatment $[27,28]$.

To improve PA uptake during cancer and among cancer survivors, evidence-based guidelines recommend the im- plementation of physical cancer rehabilitation programs (PCRPs) [6, 29-35]. Since the number of cancer survivors continues to rise, the implementation of these guidelines is an important worldwide topic $[35,36]$. Depending on the cancer site and treatment, $30-90 \%$ of cancer survivors will need physical rehabilitation [37-40].
Regrettably, it appears that adherence to current physical cancer rehabilitation (PCR) guidelines is low [41-45]. In the USA only $17 \%$ of cancer centers offer a PCRP [45], while less than $30-43 \%$ of eligible survivors worldwide participate in PCRPs [41-44, 46, 47]. Furthermore, there is scarce material on approaches to implement PCR guidelines [48-51].

Most guidelines are not fully implemented, nor diffused automatically, and formal implementation strategies are needed for them [52]. Generally, nontailored strategies directed at patients only are used to implement PCR guidelines [53]. Promising elements of tailored patient-directed strategies are patient empowerment enhancing tools $[54,55]$, often delivered by Information and Communication Technology (ICT). These tools inform and activate patients, achieving a positive impact on patient knowledge, decision-making, communication, and behavior [56-59] (e.g. educational materials [60-62] and self-management programs [63-66]). However, strategies tailored to determinants and barriers are recommended [67, 68], because tailoring is expected to contribute to implementation effectiveness [69] (odds ratios (ORs) between 1.27 and 1.93 [70]). To design tailored implementation strategies, we used the step-wise approach of the Grol and Wensing Implementation of Change Model [71, 72]. In doing so we gained insight into current practice, potential determinants [73] that predict adherence and possible barriers and facilitators $[74,75]$ influencing PCR guideline implementation. We found that barriers and determinants arise at multiple levels in the healthcare system (patient-, professional-, and/or the organizational level of care) [73-75]. That makes it very likely that a multifaceted implementation strategy will be more effective than a single-faceted (patient-directed only) implementation strategy $[72,76-80]$. We also found that abdominopelvic cavity malignancies are negative predictors for PCR guideline adherence and we found lower adherence scores for survivors of these types of tumors. So far, most strategies improving PCR guideline adherence are aimed at patients with breast cancer [53], while survivors of abdominopelvic cavity malignancies rate survivorship-care significantly lower [81, 82]. Since PCRPs for this survivor group seem cost-effective [83], it might be beneficial to design specific implementation strategies for survivors of abdominopelvic cavity malignancies. 
In this study we aimed to assess and compare the effectiveness and feasibility of two tailored strategies to implement PCR guidelines into daily care for patients who survived abdominopelvic cavity malignancies. Both strategies were designed tailored to the setting, determinants and factors found affecting implementation [71, 73-75]. We tested and compared on a patient and a cancer center level, (1) a patientdirected (PD) implementation strategy using patient empowerment tools and (2) a multifaceted (MF) implementation strategy that, apart from empowerment, additionally aims to improve compliance of healthcare professionals and the healthcare organization. We expected (hypothesis) the MF strategy to be more effective than the PD strategy, since the former intervenes at multiple levels in the healthcare system (patient-, professional-, and/or the organizational level of care).

\section{Design}

\section{Study design}

We conducted a clustered controlled before-and-after (CBA) study with cohorts in cancer centers in the Netherlands. Supplement 1 Setting gives a detailed description of the Dutch healthcare system. The study contained two arms to implement PCR guidelines: study arm (1) centers received a PD implementation strategy and study arm (2) centers received a MF implementation strategy.

\section{The implementation strategies}

The PD strategy was designed to improve the implementation of PCR guidelines by empowering patients; the MF strategy was designed to empower patients, with the additional aim of influencing their healthcare professionals and the organizational aspects. Both strategies were designed tailored to the setting, determinants found and factors affecting implementation [73-75]. See Tables 1 and 2 for the elements of both strategies. The development and selection of the implementation strategies are described in supplement 2 Strategy elements $P D$ - and MF strategy and supplement 3 Development and selection of $P D$ - and MF strategy.

Both strategies were deployed and actively carried out in the participating centers between July and December 2015 . The flyer and the interactive website were provided up until October 2017.

\section{Study population and recruitment}

The patient cohorts were recruited from the nine participating cancer centers situated in university, teaching and nonteaching hospitals or a Comprehensive Cancer Center in the
Table 1 Strategy elements PD strategy

Strategy elements

Directed to

A flyer to educate, activate, and remind patients. With information on PA and PCRPs and where information is available to guide patients' own survivorship plans

An interactive website for education and activation of patients, with information on

- Distress Thermometer (DT)

- physical oncologic rehabilitation

- PCRPs

- PCR guidelines

- web-based exercises

- care provider search

- quality assurance

Abbreviations: $P C R P$, physical cancer rehabilitation program; $P A$, physical activity; $P D$ strategy, patient-directed strategy

Table 2 Strategy elements MF strategy

\begin{tabular}{l} 
Strategy elements Directed to \\
\hline
\end{tabular}

A flyer to educate, activate, and remind patients, with Patients information on PA and PCRPs and where information is available to guide patients' own survivorship plans

An interactive website for education and activation of patients. With information on

Patients

- Distress Thermometer (DT)

- physical oncologic rehabilitation

- PCRPs

- PCR guidelines

- web-based exercises

- care provider search

- quality assurance

An interactive website for education of the healthcare Professionals professionals, with information on

- Distress Thermometer (DT)

- physical oncologic rehabilitation

- PCRPs

- PCR guidelines

- web-based exercises

- care provider search

- quality assurance

A pocket-card for healthcare professionals with

- descriptions of care pathways

- important contact details for referral to PCRPs

- the web-address of the interactive website

- contact details of the contact person in the care process for patients and professionals for the PCR guidelines process.

Outreach visits regarding PCRPs to educate healthcare professionals on regional possibilities of referral and importance of communication with patients.

Optimized description of care pathways on PCR-care

- when offering PCRP in a care pathway

- responsibility per person what and when

Improved hospital protocols on PCRP

Establishing a permanent contact person in the care process for patients and professionals for the PCR guidelines process.

Abbreviations: $M F$ strategy, multifaceted strategy; $P C R P$, physical cancer rehabilitation program; $P A$, physical activity 
Netherlands. A Comprehensive Cancer Center is a hospital entirely focused on cancer care and research. The Dutch Cancer Registry was used to select eligible patients. All patients with a history of abdominopelvic cavity malignancies (gastrointestinal, female organ, urogenital organ malignancies) were selected. After they had successfully undergone primary treatment without recurrence/metastases, they were asked for participation and informed consent by their treating healthcare professionals.

Patients diagnosed in the period from January 2014 to June 2015 were included in the before-measurement and patients diagnosed in the period from January 2016 to December 2016 were included in the after-measurement. To collect data on the characteristics of the cancer center we asked one healthcare professional per center to participate.

\section{Data collection}

Six months after the introduction of the implementation strategies the outcomes of the PD and MF strategies were measured and compared.

To gain insight into the effectiveness of both strategies, the outcomes and patient characteristics were measured with questionnaires among patients (see "Outcome measures of effectiveness" for a description of the measured outcomes). Center characteristics were assessed using the existing hospital registries systems and questionnaires among professionals involved in cancer care in the nine cancer centers. The outcomes were indicators based on national and international evidence-based PCR guidelines $[29,84,85]$ and developed by a national panel (consisting of 10 professional experts and patients) using the RANDmodified Delphi method [86, 87]. We also measured patient reported outcomes (PROs) such as quality of life, fatigue, and empowerment. The use of and experiences with the different elements of the implementation strategies were measured with patient questionnaires and the use of Google Analytics.

\section{Outcome measures of effectiveness}

\section{Primary outcome measure}

Indicator screening with the DT The questionnaire asked patients if they had received screening with the DT $[88,89]$. A photograph of the DT was shown in the questionnaire. We measured the perceived correct screening when the patients stated that they had received the DT. Supplement 4 Description of the questionnaires used gives a detailed description of the DT, as well as the other questionnaires.
Secondary outcome measures: the indicators

Information provision concerning PA and PCRPs Patients stated in the questionnaire that they had received information from the cancer center about PA and PCRPs.

Advice to take part in PA and PCRPs Patients stated that they had received advice from their healthcare professionals to improve their PA and join a PCRP.

Referral to PCRPs Patients stated that they had been referred to a PCRP.

Participation in PCRPs Patients stated that they had joined, or were joining, a PCRP mentored by either a physical therapist, a rehabilitation clinician, or a sports clinician.

PA uptake (PAU) Patients stated that their PA increased after cancer diagnosis and cancer treatment.

\section{Secondary outcome measures: patient reported outcomes} (PROs)

QoL We used the European Organization for Research and Treatment of Cancer Quality of Life Questionnaire (EORTC QLQ-C30) [90] to measure the QoL of the patients. A measurement model for the EORTC QLQ-C30 that yields a single summary score based on 13 scales (27 items) was also calculated [91].

Fatigue We used the Multidimensional Fatigue Inventory-20 (MFI-20) questionnaire $[92,93]$ to measure patient fatigue.

Patient empowerment Patient empowerment was defined as the patient's individual knowledge, skills, and confidence to manage their own health and healthcare. The state of patient empowerment was measured with the patient activity measurement-13 (PAM-13) [94, 95].

\section{Outcome measures of feasibility}

We performed a feasibility study to research the use and experiences of the different elements of the implementation strategies and the modified care.

Flyer Number of supplied flyers, rating of flyer (1-10), clear lay-out of flyer (yes/no), clear content of flyer (yes/no), flyer led to discussing PA with healthcare professional (yes/no).

Website Number of website visits, rating of website (1-10), clear lay-out of website (yes/no), clear content of website (yes/ no), website led to discussing PA with healthcare professional (yes/no). 
Professionals' pocket cards Number of pocket cards supplied to professionals.

Organization Could talk about cancer rehabilitation (yes/no), contact person available (yes/no), contact person can be easily reached (yes/no), GP involved (yes/no) and GP informed (yes/ no).

Based on the division of outcomes for implementation research described in the papers of Proctor et al. [96], we consider the indicators and the outcome of feasibility as implementation outcomes and the PROs as client outcomes.

\section{Characteristics of patients and cancer center}

The patient characteristics included were the following: age (continuous), gender (male or female), nationality (Dutch or other nationality), comorbidities $(\geq 2 /<2)$, tumor type (gastrointestinal, female organ, urogenital organ malignancies), type of treatment (surgery, chemotherapy, radiotherapy, hormonal therapy, or other), multitreatment $(\geq 2 /<2)$, weight change after cancer treatment (increase, stability, decrease), educational level (high, middle, or low), residential circumstances (alone or cohabiting), and employment status (being employed or not).

The cancer center characteristics were the following: type of hospital (Comprehensive Cancer Center, university, teaching, and nonteaching), standardized use of DT (yes or no), Multidisciplinary Oncological Rehabilitation Board (MORB) available (yes or no) and PCRP in hospital or connected medical center available (internally, externally, or not at all). A MORB is a group of healthcare professionals involved in oncological rehabilitation (e.g., surgeons, radiotherapists, medical oncologists, gynecologists, urologists, rehabilitation physicians, sports-medicine physicians, physiotherapists, physician assistants, nurses, and psychologists) interacting dynamically, interdependently, and adaptively toward common, valued rehabilitation plans for the patients.

\section{Power calculation}

The sample size calculation for the CBA study was based on the primary outcome, namely, screening with the DT. For screening we wanted to detect a percentage at the aftermeasurement of $20 \%$ in the PD strategy and $50 \%$ in the MF strategy. Assuming a two-tailed alpha of 0.05 , a power of 0.8 , and an intraclass correlation coefficient (ICC) of 0.1 , a total of 500 participants were needed. Therefore, we needed 10 hospitals with 50 patients each.

After taking into account a response rate of $50 \%$ and a dropout rate of $10 \%$, a total of at least 1100 patients needed to be invited for participation in the study.

\section{Data analysis}

We used the SAS software (SAS 9.2 for Windows from SAS Institute, Cary, North Carolina, USA) for the analyses. Descriptive analyses (frequencies, percentages, means, standard deviations (SD), medians, and ranges) were used to describe the patients and cancer center characteristics, as well as the adherence to the PROs.

Because of the hierarchical structure of our study (patients nested within cancer centers) we performed multilevel (mixed model) analyses to compare the indicators of the PD and MF strategies, as well as the differences between the characteristics of these groups. In a mixed model both fixed and random effects can be analyzed. We performed a model with a random intercept, with all other variables fixed. Multilevel linear regression analyses (Proc Mixed) were used for continuous outcome variables, while multilevel logistic regression analyses (Proc Glimmix) were used for dichotomous outcome variables.

The difference in effectiveness between both implementation strategies was tested using a model which included strategy, time, and the interaction of strategy with time as factors in the model. In these analyses, adherence to the indicators was used as dependent variables, and patient characteristics, i.e., age, gender, comorbidities $(\geq 2 /<2)$, tumor type, treatment type, weight change after cancer treatment, education level, employment status, and type of cancer center, were included as possible confounders in the model. Additionally, the differences between the beforeand after-measurements were analyzed for the PD and MF strategy groups separately. A $p$ value of $<0.05$ was statistically significant, based on two-sided tests. The ICC was calculated for each indicator to obtain insight into the clustering effect of the hospitals.

We performed descriptive statistics (frequencies, percentages, rates) on the use of and experiences with the different elements of the implementation strategies.

\section{Results}

Nine cancer centers and their patients were included in the study. (1) Five centers received a PD implementation strategy and (2) four centers received a MF implementation strategy.

Of the 1373 patients who matched the inclusion criteria and were invited for the before-measurement, 790 (58\%) responded, and 673 agreed to participate in the study, giving informed consent. Of the 1531 patients invited for the after-measurement, 745 (49\%) responded, and 653 agreed to participate in the study, giving informed consent. Thus, in total, 1326 patients were included in the two cohorts of the study. 


\section{Patient and cancer center characteristics}

Table 3 outlines the characteristics of the patients treated for the various types of cancer. We found significant differences between the groups of patients for the characteristics of age, sex, primary tumor type, amount and type of treatment, education level, and type of cancer center. Tables 4 and 5 outline the characteristics of the nine cancer centers. We found an increase of 4 cancer centers screening with the DT and a decline of 5 cancer centers offering a PCRP.

\section{Effectiveness of implementation strategies}

The scores of the indicators and PROs have been outlined in Tables 6, 7, 8, 9, 10, and 11 .

We found a significant improvement in our primary outcome measure, particularly screening with the DT between the before- and after-measurements for both strategies, respectively from 34.2 to $43.1 \%$ (delta $=8.9 \%$; OR=1.6706; $p=0.0072$ ) for the PD strategy and from 41.5 to $56.1 \%$ (delta $=14.6 \%$; OR $=1.7098 ; p=0.0028$ ) for the MF strategy. We did not find any significant differences in the other indicators, although the scores for the information provision concerning PA and PCRPs and advice to take part in PA and PCRPs both improved.

Comparing the two strategies we found that the score for the screening with the DT indicator was nonsignificantly higher for the patients of the MF strategy in comparison with the PD strategy (delta $=5.7 \%$; OR=1.0331; $p=0.8995)$. We also found no significant differences in the other indicators. The ICCs of the scores of the indicators varied between 0 and 0.091, and of the PROs between 0 and 0.057 .

\section{Feasibility}

In total, 632 patients of the after-measurement were included in this analysis. We supplied 5000 flyers to the nine cancer centers and 50 pocket cards to the cancer centers used for the MF strategy. The website was visited 911 times by 766 different individuals. The outcomes of the feasibility study have been outlined in Tables 12 and 13 .

Eighty-two percent out of the $56 \%$ of the total patients receiving the flyer actually read it.

The median score for the flyer was 8. Eighty-eight percent of the patients agreed that the flyer had clear content and a clear lay-out. Sixty-one percent mentioned that it led them to discuss PA with their healthcare professionals.

Of the $29 \%$ of the total patients using the website, $73 \%$ agreed that the website had clear content and a clear lay-out. The median score for the website was 7 . Seventy-five percent of the patients using the website agreed that the website stimulated discussion of PA with their care professionals.
In the cancer centers that participated, $90 \%$ of the patients confirmed that they were offered the option to talk with a healthcare professional about cancer rehabilitation during or after treatment.

\section{Discussion}

We investigated the effectiveness and feasibility of two tailored strategies to increase the adherence to PCR guidelines for patients who had been treated for and survived abdominopelvic cavity malignancies in this clustered CBA study. We found that both PD and MF strategies significantly improved our primary outcome measure, particularly the score of screening with the DT. The MF implementation strategy showed more improvement, though the difference with the PD strategy did not appear to be significant.

We did not find any significant improvement in the other indicators, although we did find good use of, and experience with, both strategies.

\section{Indicator score}

As expected from our previous study and other literature [47, $73,81,82,97-100$ ], we found low adherence scores for survivors of abdominopelvic cavity malignancies. Other studies showed a substantial proportion of cancer survivors with unmet needs after their cancer treatment [97-100], while onethird of the survivors lacked information about PCRPs and other survivorship-care [47]. Both tested strategies seemed able to improve this aspect of survivorship-care. The scores of the proximal implementation outcomes, (1) screening with the DT, (2) information provision concerning PA and PCRPs, and (3) advice to take part in PA and PCRPs all improved. Even so, only the improved score of screening with the DT was shown to be significant.

Unfortunately, the scores for the more distal implementation outcomes, (1) referral to PCRPs and (2) participation in PCRPs and (3) PAU, and the client outcomes, (1) fatigue, (2) QoL, and (3) empowerment remained stable or decreased slightly. An explanation could be that the time interval between the introduction of the strategies in the centers and the start of the aftermeasurement was too short, since the more distal implementation outcomes and the client outcomes measure the effect later on in the process of survivorship-care. Implementation strategies often need more time to influence the more distal implementation outcomes and the client outcomes. Evidence of the effectiveness of both strategies in the long term is still questionable and further exploration is needed.

Additionally, a dramatic change in Dutch PCR care and its reimbursement could also be a cause (Supplement 1 Setting). Patients included in the before-measurement were able to attend the PCRP called "Recovery \& 
Table 3 Patient characteristics

\begin{tabular}{|c|c|c|c|c|c|}
\hline & \multicolumn{2}{|l|}{ PD strategy } & \multicolumn{2}{|l|}{ MF strategy } & \multirow[t]{2}{*}{$p^{* *}$} \\
\hline & Before-measurement & After-measurement & Before-measurement & After-measurement & \\
\hline No. of patients & 353 & 261 & 320 & 392 & \\
\hline \multirow[t]{3}{*}{ Age, years } & Mean (SD) & Mean (SD) & Mean (SD) & Mean (SD) & 0.0013 \\
\hline & $68.4(10.0)$ & $67.4(10.3)$ & $67.3(11.7)$ & $65.1(12.8)$ & \\
\hline & No. $(\% *)$ & No. $(\% *)$ & No. $(\% *)$ & No. $(\% *)$ & \\
\hline Sex & & & & & $<0.0001$ \\
\hline Female & $109(31.3)$ & $73(28.5)$ & $181(57.8)$ & $266(68.6)$ & \\
\hline Male & $239(68.7)$ & $183(71.5)$ & $132(42.2)$ & $122(31.4)$ & \\
\hline Dutch & & & & & 0.6048 \\
\hline Yes & $321(92.7)$ & $229(89.8)$ & 285 (91.9) & $351(92.1)$ & \\
\hline No & $25(7.2)$ & $26(10.2)$ & $25(8.1)$ & $30(7.9)$ & \\
\hline Primary tumor type & & & & & $<0.0001$ \\
\hline Female organs & $45(12.8)$ & $37(14.2)$ & $115(35.9)$ & $223(56.9)$ & \\
\hline Urogenital organs & $205(58.1)$ & $154(59.0)$ & $31(9.7)$ & $28(7.1)$ & \\
\hline Gastrointestinal & $103(29.2)$ & $70(26.8)$ & $174(54.4)$ & $141(36.0)$ & \\
\hline \multicolumn{6}{|l|}{ Treatment } \\
\hline Surgery & $269(76.2)$ & 187 (71.7) & $289(90.3)$ & $336(85.9)$ & $<0.0001$ \\
\hline Chemotherapy & $104(29.5)$ & $76(29.1)$ & $118(36.9)$ & $148(37.8)$ & 0.0220 \\
\hline Radiotherapy & $107(30.3)$ & $69(26.4)$ & $80(25.0)$ & $99(25.3)$ & 0.3556 \\
\hline Hormonal therapy & $48(13.6)$ & $26(10.0)$ & $15(4.7)$ & $19(4.9)$ & $<0.0001$ \\
\hline Other & $27(7.7)$ & $24(9.2)$ & $11(3.4)$ & $16(4.1)$ & 0.0048 \\
\hline No of treatments & & & & & 0.0141 \\
\hline$<2$ & $199(56.4)$ & $164(62.8)$ & $162(50.6)$ & $204(52.0)$ & \\
\hline$\geq 2$ & $154(43.6)$ & $97(37.2)$ & $158(49.4)$ & $188(48.0)$ & \\
\hline No of comorbidities & & & & & 0.2415 \\
\hline$<2$ & $244(69.1)$ & 195 (74.7) & $224(70.0)$ & $264(67.4)$ & \\
\hline$\geq 2$ & 109 (30.9) & $66(25.3)$ & $96(30.0)$ & $128(32.7)$ & \\
\hline Weight after treatment & & & & & 0.1167 \\
\hline Increase & $118(34.3)$ & $66(25.8)$ & $110(35.7)$ & $140(36.9)$ & \\
\hline Stable & $182(52.9)$ & $146(57.3)$ & $154(50.0)$ & 189 (49.9) & \\
\hline Decrease & $44(12.8)$ & $43(16.9)$ & $44(14.3)$ & $50(13.2)$ & \\
\hline Living circumstances & & & & & 0.4024 \\
\hline Alone & $66(18.9)$ & $47(18.2)$ & $72(22.5)$ & $86(22.3)$ & \\
\hline Cohabiting & $283(81.1)$ & $212(81.9)$ & $248(77.5)$ & $300(77.7)$ & \\
\hline Education level & & & & & 0.0482 \\
\hline Low & $131(37.4)$ & $79(30.7)$ & $127(39.9)$ & $139(36.3)$ & \\
\hline Middle & $125(35.7)$ & $96(37.4)$ & $125(39.3)$ & $155(40.5)$ & \\
\hline High & $94(26.9)$ & $82(31.9)$ & $66(20.8)$ & $89(23.2)$ & \\
\hline Employment status & & & & & 0.0731 \\
\hline Working & $70(20.5)$ & $61(23.7)$ & $73(23.5)$ & $110(28.7)$ & \\
\hline Nonworking & $272(79.5)$ & $196(76.3)$ & $238(76.5)$ & $273(71.3)$ & \\
\hline Type of cancer center & & & & & $<0.0001$ \\
\hline Categorical & $0(0.0)$ & $0(0.0)$ & $55(17.2)$ & $126(32.1)$ & \\
\hline University & $156(44.2)$ & $119(45.6)$ & $49(15.3)$ & $89(22.7)$ & \\
\hline Teaching & $55(15.6)$ & $35(13.4)$ & $111(34.7)$ & $107(27.3)$ & \\
\hline Nonteaching & $142(40.2)$ & $107(41.0)$ & $105(32.8)$ & $70(17.9)$ & \\
\hline
\end{tabular}

Abbreviations: No, number of; $M F$ strategy, multifaceted strategy; $P D$ strategy, patient-directed strategy; $p, p$ value

*Valid percentage

**Comparison analysis of the characteristics of the patients included in the before-measurement PD strategy, after-measurement PD strategy, beforemeasurement MF strategy, and after-measurement MF strategy 
Table 4 Characteristics of the cancer centers PD strategy

\begin{tabular}{|c|c|c|c|c|c|c|c|c|c|c|}
\hline \multirow[b]{2}{*}{ Type of center } & \multicolumn{2}{|l|}{ Center 1} & \multicolumn{2}{|l|}{ Center 2} & \multicolumn{2}{|l|}{ Center 3} & \multicolumn{2}{|l|}{ Center 4} & \multicolumn{2}{|l|}{ Center 5} \\
\hline & & & & & & & & & & \\
\hline \multicolumn{11}{|l|}{ Categorical } \\
\hline University & $\sqrt{ }$ & & & & & & & & & \\
\hline Teaching & & & & & $\sqrt{ }$ & & & & & \\
\hline Nonteaching & & & $\sqrt{ }$ & & & & $\sqrt{ }$ & & $\sqrt{ }$ & \\
\hline \multicolumn{11}{|l|}{ MORB available } \\
\hline & Before & After & Before & After & Before & After & Before & After & Before & After \\
\hline Screening DT & & $\sqrt{ }$ & $\sqrt{ }$ & $\sqrt{ }$ & $\sqrt{ }$ & $\sqrt{ }$ & & $\sqrt{ }$ & $\sqrt{ }$ & $\sqrt{ }$ \\
\hline \multicolumn{11}{|c|}{ PCRP/physiotherapy } \\
\hline Internal PCRP & & & & & $\sqrt{ }$ & & & & & \\
\hline External PCRP & $\sqrt{ }$ & $\sqrt{ }$ & $\sqrt{ }$ & & & & & & $\sqrt{ }$ & \\
\hline Physiotherapy & & $\sqrt{ }$ & & $\sqrt{ }$ & & $\sqrt{ }$ & & & & $\sqrt{ }$ \\
\hline
\end{tabular}

Abbreviations: DT, Distress Thermometer; $M O R B$, Multidisciplinary Oncological Rehabilitation Board; $P C R P$, physical cancer rehabilitation program; $P D$ strategy, patient-directed strategy

Balance". Patients included in the after-measurement were confronted with a new system of PCRPs. From our feasibility study we know that patients experienced stricter accessibility conditions, waiting lists and ensuing costs (fewer reimbursement options) of joining a PCRP for these programs. Unfortunately, our study lacks a control group; we did not consider the unexpected alteration of adherence due to changes in cancer rehabilitation care offered during the intervention period.

Improved implementation outcomes might have a mediation effect on the client outcomes. A mediation analysis could be used to analyze the mediation effect of the implementation outcomes on the more distal client outcomes. However, we did not find a significant effect of the implementation strategies on the client outcomes, and therefore we do not expect to find a mediation effect of the implementation outcomes via a mediation analysis. An additional study designed to evaluate this mediation effect is needed.

\section{Empowerment tools}

Using strategies with patient empowerment enhancing tools, we improved the proximal implementation outcomes, (1) screening with the DT, (2) information provision concerning PA and PCRPs, and (3) advice to take part in PA and PCRPs. The empowerment enhancing tools consisted of educational

Table 5 Characteristics of the cancer centers MF strategy

\begin{tabular}{|c|c|c|c|c|c|c|c|c|}
\hline & Center 6 & & Center 7 & & Center 8 & & Center 9 & \\
\hline \multicolumn{9}{|l|}{ Type of center } \\
\hline \multicolumn{9}{|l|}{ Categorical } \\
\hline \multicolumn{9}{|l|}{ University } \\
\hline \multicolumn{9}{|l|}{ Teaching } \\
\hline \multicolumn{9}{|l|}{ Nonteaching } \\
\hline \multirow[t]{2}{*}{ MORB available } & $\sqrt{ }$ & & & & & & & \\
\hline & Before & After & Before & After & Before & After & Before & After \\
\hline Screening DT & $\sqrt{ }$ & $\sqrt{ }$ & & $\sqrt{ }$ & $\sqrt{ }$ & $\sqrt{ }$ & & $\sqrt{ }$ \\
\hline \multicolumn{9}{|c|}{ PCRP/physiotherapy } \\
\hline Internal PCRP & $\sqrt{ }$ & $\sqrt{ }$ & & & $\sqrt{ }$ & & $\sqrt{ }$ & \\
\hline External PCRP & & & $\sqrt{ }$ & $\sqrt{ }$ & & & & \\
\hline Physiotherapy & & $\sqrt{ }$ & & $\sqrt{ }$ & & $\sqrt{ }$ & & $\sqrt{ }$ \\
\hline
\end{tabular}

Abbreviations: DT, Distress Thermometer; MF strategy, multifaceted strategy; MORB, Multidisciplinary Oncological Rehabilitation Board; PCRP, physical cancer rehabilitation program 
Table 6 Quality indicators PD strategy

\begin{tabular}{|c|c|c|c|c|c|c|c|}
\hline & \multirow{2}{*}{$\begin{array}{l}\text { Before } \\
\text { No }(\% *)\end{array}$} & \multirow{2}{*}{$\begin{array}{l}\text { After } \\
\text { No }(\% *)\end{array}$} & \multirow[t]{2}{*}{ Delta } & \multicolumn{2}{|c|}{ Change uncorrected } & \multicolumn{2}{|c|}{ Change corrected } \\
\hline & & & & OR & $p$ & OR** & $p$ \\
\hline \multicolumn{8}{|c|}{ Screening with the DT } \\
\hline Yes & $120(34.2)$ & $112(43.1)$ & 8.9 & 1.6349 & 0.0060 & 1.6706 & 0.0072 \\
\hline No & $231(65.8)$ & $148(56.9)$ & & & & & \\
\hline \multicolumn{8}{|c|}{ Information provision concerning PA and PCRPs } \\
\hline Yes & $129(37.5)$ & $109(42.8)$ & 5.3 & 1.2013 & 0.2923 & 1.2663 & 0.1962 \\
\hline No & $215(62.5)$ & $146(57.3)$ & & & & & \\
\hline \multicolumn{8}{|c|}{ Advice to take part in PA and PCRPs } \\
\hline Yes & $176(50.3)$ & $142(54.6)$ & 4.3 & 1.1833 & 0.3150 & 1.3147 & 0.1370 \\
\hline No & $174(49.7)$ & $118(45.4)$ & & & & & \\
\hline \multicolumn{8}{|c|}{ Referral to PCRPs } \\
\hline Yes & $39(11.2)$ & $24(9.3)$ & -1.9 & 0.8115 & 0.4463 & 0.8148 & 0.4975 \\
\hline No & $310(88.8)$ & $235(90.7)$ & & & & & \\
\hline
\end{tabular}

Abbreviations: No, number of; $O R$, odds ratio; $P A$, physical activity; $P C R P$, physical cancer rehabilitation program; $P D$ strategy, patient-directed strategy; $p, p$ value

*Valid percentage

**In the effect analyses, adherence to the indicators was used as dependent variables, and patient characteristics that showed significant intergroup differences, i.e., age, gender, comorbidities $(\geq 2 /<2)$, tumor type, treatment type, weight change after cancer treatment, education level, employment status, and type of cancer center, were included as possible confounders in the model of the outcomes of the effect of the strategies

Table 7 Patient reported outcomes PD strategy

\begin{tabular}{|c|c|c|c|c|c|c|c|}
\hline & \multirow{2}{*}{$\begin{array}{l}\text { Before } \\
\text { No }(\% *)\end{array}$} & \multirow{2}{*}{$\begin{array}{l}\text { After } \\
\text { No }(\% *)\end{array}$} & \multirow[t]{2}{*}{ Delta } & \multicolumn{2}{|c|}{ Change uncorrected } & \multicolumn{2}{|c|}{ Change corrected } \\
\hline & & & & OR & $p$ & $\mathbf{O R}^{* *}$ & $p$ \\
\hline \multicolumn{8}{|l|}{ Participation in PCRPs } \\
\hline Yes & $70(20.1)$ & $53(20.7)$ & 0.6 & 1.0246 & 0.9069 & 1.0653 & 0.7783 \\
\hline No & 278 (79.9) & $203(79.3)$ & & & & & \\
\hline \multicolumn{8}{|l|}{ PAU } \\
\hline Yes & $140(40.1)$ & 97 (37.7) & -2.4 & 0.9050 & 0.5544 & 0.9381 & 0.7250 \\
\hline \multirow[t]{2}{*}{ No } & $209(59.9)$ & $160(62.3)$ & & & & & \\
\hline & Mean (SD) & Mean (SD) & Delta & Change & $p$ & Change & $p$ \\
\hline \multicolumn{8}{|l|}{ EORTC QLQ-C30 } \\
\hline Mean summary score & $40.6(5.6)$ & $40.6(5.7)$ & 0.0 & 0.09838 & 0.8344 & 0.3144 & 0.5052 \\
\hline Global health status/QoL & $77.1(18.1)$ & $78.4(18.2)$ & 1.3 & 1.1599 & 0.4466 & 1.1688 & 0.4233 \\
\hline Physical function & $85.3(16.5)$ & $85.6(17.7)$ & 0.3 & 0.1142 & 0.9356 & 0.07302 & 0.9547 \\
\hline \multicolumn{8}{|l|}{ MFI-20 score } \\
\hline Mean general fatigue & $9.3(4.4)$ & $9.7(4.6)$ & .4 & 0.4881 & 0.1908 & 0.5177 & 0.1525 \\
\hline Mean physical fatigue & $9.2(4.2)$ & $9.4(4.5)$ & .2 & 0.3205 & 0.3699 & 0.3726 & 0.2875 \\
\hline \multicolumn{8}{|l|}{ PAM-13 } \\
\hline Mean total score & $56.8(12.9)$ & $55.6(12.6)$ & -1.2 & -1.1979 & 0.2981 & -1.6979 & 0.1615 \\
\hline
\end{tabular}

Abbreviations: EORTC QLQ-C30, The European Organization for Research and Treatment of Cancer Quality of Life Questionnaire; MFI-20, Multidimensional Fatigue Inventory-20; No, number of; $P A M-13$, Patient Activity Measurement-13; PCRP, physical cancer rehabilitation program; $P A U$, physical activity uptake; $P D$ strategy, patient-directed strategy; $p, p$ value; $S D$, standard deviation

*Valid percentage

**In the effect analyses, adherence to the indicators was used as dependent variables, and patient characteristics that showed significant intergroup differences, i.e., age, gender, comorbidities $(\geq 2 /<2)$, tumor type, treatment type, weight change after cancer treatment, education level, employment status, and type of cancer center, were included as possible confounders in the model of the outcomes of the effect of the strategies 
Table 8 Quality indicators MF strategy

\begin{tabular}{|c|c|c|c|c|c|c|c|}
\hline & \multirow{2}{*}{$\begin{array}{l}\text { Before } \\
\text { No }(\% *)\end{array}$} & \multirow{2}{*}{$\begin{array}{l}\text { After } \\
\text { No }(\% *)\end{array}$} & \multirow[t]{2}{*}{ Delta } & \multicolumn{2}{|c|}{ Change uncorrected } & \multicolumn{2}{|c|}{ Change corrected } \\
\hline & & & & OR & $p$ & OR** & $p$ \\
\hline \multicolumn{8}{|c|}{ Screening with the DT } \\
\hline Yes & $131(41.5)$ & $220(56.1)$ & 14.6 & 1.5713 & 0.0052 & 1.7098 & 0.0028 \\
\hline No & $185(58.5)$ & $172(43.9)$ & & & & & \\
\hline \multicolumn{8}{|c|}{ Information provision concerning PA and PCRPs } \\
\hline Yes & $122(39.4)$ & $162(42.6)$ & 3.2 & 1.1839 & 0.3015 & 1.2896 & 0.1398 \\
\hline No & $188(60.7)$ & $218(57.4)$ & & & & & \\
\hline \multicolumn{8}{|c|}{ Advice to take part in PA and PCRPs } \\
\hline Yes & $164(51.9)$ & $220(56.9)$ & 5.0 & 1.1785 & 0.2939 & 1.1284 & 0.4871 \\
\hline No & $152(48.1)$ & $167(43.2)$ & & & & & \\
\hline \multicolumn{8}{|c|}{ Referral to PCRPs } \\
\hline Yes & $45(14.3)$ & $51(13.4)$ & -0.9 & 0.9171 & 0.7070 & 1.0093 & 0.9707 \\
\hline No & $269(85.7)$ & 329 (86.6) & & & & & \\
\hline
\end{tabular}

Abbreviations: No, number of; $M F$ strategy, multifaceted strategy; $O R$, odds ratio; $P A$, physical activity; $P C R P$, physical cancer rehabilitation program; $p, p$ value

*Valid percentage

** In the effect analyses, adherence to the indicators was used as dependent variables, and patient characteristics that showed significant intergroup differences, i.e., age, gender, comorbidities $(\geq 2 /<2)$, tumor type, treatment type, weight change after cancer treatment, education level, employment status, and type of cancer center, were included as possible confounders in the model of the outcomes of the effect of the strategies

Table 9 Patient reported outcomes MF strategy

\begin{tabular}{|c|c|c|c|c|c|c|c|}
\hline & \multirow{2}{*}{$\begin{array}{l}\text { Before } \\
\text { No }(\% *)\end{array}$} & \multirow{2}{*}{$\begin{array}{l}\text { After } \\
\text { No }(\% *)\end{array}$} & \multirow[t]{2}{*}{ Delta } & \multicolumn{2}{|c|}{ Change uncorrected } & \multicolumn{2}{|c|}{ Change corrected } \\
\hline & & & & OR & $p$ & $\mathbf{O R} * *$ & $p$ \\
\hline \multicolumn{8}{|l|}{ Participation in PCRPs } \\
\hline Yes & $77(24.6)$ & $75(19.8)$ & -4.8 & 0.7216 & 0.0864 & 0.7137 & 0.0990 \\
\hline No & $236(75.4)$ & $303(80.2)$ & & & & & \\
\hline \multicolumn{8}{|l|}{ PAU } \\
\hline Yes & $140(44.6)$ & $165(43.0)$ & -1.6 & 0.8860 & 0.4471 & 0.9896 & 0.9363 \\
\hline \multirow[t]{2}{*}{ No } & $174(55.4)$ & $219(57.0)$ & & & & & \\
\hline & Mean (SD) & Mean (SD) & Delta & Change & $p$ & Change & $p$ \\
\hline \multicolumn{8}{|l|}{ EORTC QLQ-C30 } \\
\hline Mean summary score & $41.1(5.1)$ & $41.4(6.1)$ & 0.3 & 0.1552 & 0.7282 & 0.08138 & 0.8585 \\
\hline Global health status/QoL & $78.0(17.7)$ & $77.3(17.6)$ & 0.7 & 0.5088 & 0.7074 & 0.4964 & 0.7004 \\
\hline Physical function & $81.4(19.0)$ & $82.7(17.7)$ & 1.3 & 1.8064 & 0.2009 & 1.6891 & 0.2008 \\
\hline \multicolumn{8}{|l|}{ MFI-20 score } \\
\hline Mean general fatigue & $9.9(4.5)$ & $10.3(4.6)$ & 0.4 & -0.0403 & 0.9085 & -0.0395 & 0.9070 \\
\hline Mean physical fatigue & $9.6(4.5)$ & $10.0(4.4)$ & 0.4 & 0.1448 & 0.6769 & 0.2429 & 0.4684 \\
\hline \multicolumn{8}{|l|}{ PAM-13 } \\
\hline Mean total score & $55.9(13.9)$ & $54.7(13.1)$ & -1.2 & -1.1699 & 0.2515 & -1.0151 & 0.3378 \\
\hline
\end{tabular}

Abbreviations: EORTC QLQ-C30, The European Organization for Research and Treatment of Cancer Quality of Life Questionnaire; MFI-20, Multidimensional Fatigue Inventory-20; $M F$ strategy, multifaceted strategy; $N o$, number of; $P A M-13$, Patient Activity Measurement-13; PCRP, physical cancer rehabilitation program; $P A U$, physical activity uptake; $p, p$ value; $S D$, standard deviation

*Valid percentage

**In the effect analyses, adherence to the indicators was used as dependent variables, and patient characteristics that showed significant intergroup differences, i.e., age, gender, comorbidities $(\geq 2 /<2)$, tumor type, treatment type, weight change after cancer treatment, education level, employment status, and type of cancer center, were included as possible confounders in the model of the outcomes of the effect of the strategies 
Table 10 Quality indicators MF strategy minus PD strategy

\begin{tabular}{|c|c|c|c|c|}
\hline Delta & \multicolumn{2}{|c|}{ Difference uncorrected } & \multicolumn{2}{|c|}{ Difference corrected } \\
\hline No $(\% *)$ & OR ratio & $p$ & OR ratio** & $p$ \\
\hline \multicolumn{5}{|l|}{ Screening with the DT } \\
\hline 5.7 & 1.0586 & 0.8130 & 1.0331 & 0.8995 \\
\hline \multicolumn{5}{|c|}{ Information provision concerning PA and PCRPs } \\
\hline-2.1 & 0.9923 & 0.9741 & 0.9918 & 0.9734 \\
\hline \multicolumn{5}{|c|}{ Advice to take part in PA and PCRPs } \\
\hline 0.7 & 0.9913 & 0.9695 & 1.1085 & 0.6804 \\
\hline \multicolumn{5}{|l|}{ Referral to PCRPs } \\
\hline 1.0 & 0.8907 & 0.7497 & 0.8236 & 0.6215 \\
\hline
\end{tabular}

Abbreviations: No, number of; $M F$ strategy, multifaceted strategy; $O R$, odds ratio; $P A$, physical activity; $P C R P$, physical cancer rehabilitation program; $P D$ strategy, patient-directed strategy; $p, p$ value

*Valid percentage

**In the effect analyses, adherence to the indicators was used as dependent variables, and patient characteristics that showed significant intergroup differences, i.e., age, gender, comorbidities $(\geq 2 /<2)$, tumor type, treatment type, weight change after cancer treatment, education level, employment status, and type of cancer center, were included as possible confounders in the model of the outcomes of the effect of the strategies materials, self-management tools, and reminders via flyers and a website. In the process of rehabilitation, empowerment enhancing tools can have extra value, since confidence to take charge, decision making and belief in oneself can directly affect the efficacy of the rehabilitation [101]. Sufficient empowerment enables individuals to influence their own
Table 11 Patient reported outcomes MF strategy minus PD strategy

\begin{tabular}{|c|c|c|c|c|c|}
\hline & \multirow{2}{*}{$\begin{array}{l}\text { Delta } \\
\text { No }(\% *)\end{array}$} & \multicolumn{2}{|c|}{ Difference uncorrected } & \multicolumn{2}{|c|}{ Difference corrected } \\
\hline & & OR ratio & $p$ & OR ratio** & $p$ \\
\hline \multicolumn{6}{|l|}{ Participation in PCRPs } \\
\hline & -4.2 & 1.3939 & 0.2382 & 1.4133 & 0.2506 \\
\hline \multicolumn{6}{|l|}{ PAU } \\
\hline & 0.8 & 1.0072 & 0.9756 & 1.0128 & 0.9583 \\
\hline & Mean & Difference & $p$ & Difference & $p$ \\
\hline \multicolumn{6}{|l|}{ EORTC QLQ-C30 } \\
\hline Mean summary score & 0.3 & -0.06646 & 0.9187 & 0.2656 & 0.6841 \\
\hline Global health status/QoL & -0.6 & 0.6913 & 0.7340 & 0.6273 & 0.7449 \\
\hline Physical function & 1.0 & -1.6934 & 0.3999 & -1.3749 & 0.4616 \\
\hline \multicolumn{6}{|l|}{ MFI-20 score } \\
\hline Mean general fatigue & 0.0 & 0.5183 & 0.3186 & 0.5723 & 0.2449 \\
\hline Mean physical fatigue & 0.2 & 0.1675 & 0.7406 & 0.2097 & 0.6657 \\
\hline \multicolumn{6}{|l|}{ PAM-13 } \\
\hline Mean total score & 0.0 & -0.0218 & 0.9886 & -1.1235 & 0.4843 \\
\hline
\end{tabular}

Abbreviations: EORTC QLQ-C30, The European Organization for Research and Treatment of Cancer Quality of Life Questionnaire; MFI-20, Multidimensional Fatigue Inventory-20; MF strategy, multifaceted strategy; No, number of; $O R$, odds ratio; $P A M-13$, Patient Activity Measurement-13; $P C R P$, physical cancer rehabilitation program; $P A U$, physical activity uptake; $P D$ strategy, patient-directed strategy; $p, p$ value

*Valid percentage

**In the effect analyses, adherence to the indicators was used as dependent variables, and patient characteristics that showed significant intergroup differences, i.e., age, gender, comorbidities $(\geq 2 /<2)$, tumor type, treatment type, weight change after cancer treatment, education level, employment status, and type of cancer center, were included as possible confounders in the model of the outcomes of the effect of the strategies 
Table 12 Feasibility flyer and website
Total

\section{Flyer $(n=244)$}

Median rate score

8 out of 10

No $(\% *)$

137 (56)

Remembered receiving flyer

Read flyer after receiving it

$112(82)$

Agreed clear lay-out and content

$98(88)$

Agreed flyer stimulates discussion of PA with their healthcare professionals

$68(61)$

Website $(n=624)$

Median rate score

7 out of 10

No $(\%$ *)

$180(29)$

Used website

144 (73)

Agreed clear lay-out and content

$131(75)$

Agreed website stimulates discussion of PA with their healthcare professionals

Reasons given for not using the website were no internet or computer (skills), patient already performed enough PA, preference for personal contact instead of written information or information via ICT systems, sufficient knowledge already about PA during and after cancer, and unaware of existence of website.

Abbreviations: No, number of; $M F$ strategy, multifaceted strategy; $P A$, physical activity; $P D$ strategy, patientdirected strategy

*Valid percentage behavior and that of their healthcare professionals [102].

Empowerment enhancing tools are positively associated with improved PA [103-105] and studies showed positive experiences of patients with these tools to support survivorship-care

Table 13 Feasibility organization

\begin{tabular}{|c|c|c|c|}
\hline & Total & PD strategy & MF strategy \\
\hline & No $(\% *)$ & No $(\% *)$ & No $(\% *)$ \\
\hline \multicolumn{4}{|c|}{ Organization $(N=632)$} \\
\hline \multicolumn{4}{|c|}{ Could talk about cancer rehabilitation } \\
\hline Yes & $550(90)$ & $216(88)$ & $334(92)$ \\
\hline No & $59(10)$ & $30(12)$ & $29(8)$ \\
\hline \multicolumn{4}{|c|}{ Contact person available } \\
\hline Yes & $442(71)$ & $161(66)$ & $281(75)$ \\
\hline No & $177(29)$ & $84(34)$ & $93(25)$ \\
\hline \multicolumn{4}{|c|}{ Contact person easily reachable } \\
\hline Yes & $424(83)$ & $159(82)$ & $265(84)$ \\
\hline No & $85(17)$ & $36(18)$ & $49(16)$ \\
\hline \multicolumn{4}{|c|}{ GP involved } \\
\hline Yes & $450(71)$ & $164(65)$ & $286(76)$ \\
\hline No & $182(29)$ & $89(35)$ & $93(24)$ \\
\hline \multicolumn{4}{|c|}{ GP informed } \\
\hline Yes & $531(87)$ & $201(82)$ & $330(90)$ \\
\hline No & $80(13)$ & $43(18)$ & $37(10)$ \\
\hline
\end{tabular}

Reasons given for no referral or PCRP participation were insufficient insurance coverage and the ensuing costs of joining a PA program, waiting lists because of lack of capacity, referral offered at inconvenient times in the treatment process, nontailored PCRPs, patient already performed enough PA, coordination of cancer treatment in cancer treatment facility that does not participate in this study, and negative advice of healthcare professionals.

Abbreviations: $G P$, general practitioner; No, number of; $M F$ strategy, multifaceted strategy; $P A$, physical activity; $P C R P$, physical cancer rehabilitation program; $P D$ strategy, patient-directed strategy

*Valid percentage 
[106]. Therefore, these tools have the potential to fulfill the unmet needs of patients with cancer and after cancer treatment.

\section{Clustered trial}

We performed a clustered CBA study with cohorts in nine cancer centers. The ICC is defined as the ratio of the between-cluster variance to the total variance. An ICC of 0 indicates that individuals within clusters are no more like each other than individuals from different clusters (there is no between-cluster variability), while an ICC of 1 indicates that individuals within the same cluster all have identical outcomes (there is no within-cluster variability). ICC values between 0 and 0.40 were found in other comparable research [107], while the ICCs of the implementation- and client outcomes in our study varied between 0 and 0.091 , predicting a low chance of between cluster variability. For our power analysis we assumed an ICC of 0.1 , which adjusted possible clustering.

\section{Strengths and limitations}

Our study has several strengths. This is one of the few largescale studies to develop and test two strategies to implement PCR guidelines into daily healthcare. We were able to include 1326 patients from nine cancer centers. Secondly, the originality of our study is further supported by the fact that it is one of the few studies comparing the effect of a PD strategy with an MF strategy. Thirdly, this is the first time that two different strategies leading to adherence to PCR guidelines were assessed with implementation outcomes based on indicators that were based on national and international evidence-based PCR guidelines. Furthermore, clinical practice was left undisturbed as much as possible, allowing for an estimation of the actual effect of the strategies in a nonresearch setting. The tools developed were tailored to current PCR guideline adherence and perceived determinants [73] and barriers [74, 75] influencing PCR guideline implementation. Finally, besides the effectiveness of the strategies, we also contributed a feasibility study.

A limitation of our study is that due to collaborations between cancer centers patients might have been treated in more than one center. Therefore, there might have been an amalgamation of results between the PD and MF strategies or with centers where no strategy was applied. Also, the time interval between the introduction of the developed strategies in the centers and the start of the after-measurement was short. In our experience it often takes a while for strategies to influence daily clinical practice. The time period was probably too short to really measure the influence of the strategies on most of the outcomes, particularly the effect on the secondary outcomes (the more distal implementation outcomes and client outcomes) that measured the implementation after screening with the DT.
Another limitation is the absence of a proper randomized study design that would have eliminated bias in implementation strategy assignment and ensured that the differences in outcomes between the implementation strategies indicated significant effects on PCR guideline implementation [108]. However, it is known that comparing complex interventions and convincing centers to participate in implementation research concerning the whole treatment pathway are a challenging matter, for which one must settle with less advanced, but still feasible study designs. Evidence of the effectiveness and experiences with both strategies longer-term is still questionable and further exploration is needed.

Finally, we did not look at the international setting but only at the Dutch healthcare setting. Various European guidelines also advise on PCRPs. The incentive to start PCRPs might be different in other countries with different healthcare systems and often even more limited reimbursement policies. Although more research is needed to assess the effectiveness and feasibility of implementation strategies in other countries, our personal impression is that the findings may well be applicable to other countries.

\section{Conclusion}

This study showed that the PD and MF strategies containing empowerment enhancing tools were both effective in increasing the amount of screening with the DT for survivors of abdominopelvic cavity malignancies. The MF implementation strategy that, apart from empowerment, additionally aims to improve compliance of healthcare professionals and the healthcare organization showed more improvement, though the difference with the PD strategy did not appear to be significant. A randomized study design is needed to establish causality between the strategies and the implementation of PCR guidelines.

Supplementary Information The online version contains supplementary material available at https://doi.org/10.1007/s11764-021-01045-3.

Funding This work was supported by the Dutch Cancer Society [Grant no. NKI 2010-4854].

Data availability All data generated or analyzed in this study are included in this published article and its supplementary information files.

\section{Declarations}

Ethics approval and consent to participate The regional review board for human research assessed the study (CMO Arnhem-Nijmegen dossier number 2014/211] and judged that ethics approval was not required under Dutch national law. The study was performed in accordance with the 
privacy legislation. Informed consent was obtained from all individual participants included in the study.

\section{Consent for publication Not applicable.}

Competing interests The authors declare that they have no competing interests.

Open Access This article is licensed under a Creative Commons Attribution 4.0 International License, which permits use, sharing, adaptation, distribution and reproduction in any medium or format, as long as you give appropriate credit to the original author(s) and the source, provide a link to the Creative Commons licence, and indicate if changes were made. The images or other third party material in this article are included in the article's Creative Commons licence, unless indicated otherwise in a credit line to the material. If material is not included in the article's Creative Commons licence and your intended use is not permitted by statutory regulation or exceeds the permitted use, you will need to obtain permission directly from the copyright holder. To view a copy of this licence, visit http://creativecommons.org/licenses/by/4.0/.

\section{References}

1. Mishra SI, Scherer RW, Geigle PM, Berlanstein DR, Topaloglu $\mathrm{O}$, Gotay CC, et al. Exercise interventions on health-related quality of life for cancer survivors. Cochrane Database Syst Rev. 2012;8:CD007566.

2. Cramp F, Byron-Daniel J. Exercise for the management of cancerrelated fatigue in adults. Cochrane Database Syst Rev. 2012;11: CD006145.

3. Markes M, Brockow T, Resch KL. Exercise for women receiving adjuvant therapy for breast cancer. Cochrane Database Syst Rev. 2006;4:CD005001.

4. van Waart H, Stuiver MM, van Harten WH, Geleijn E, Kieffer JM, Buffart LM, et al. Effect of low-intensity physical activity and moderate- to high-intensity physical exercise during adjuvant chemotherapy on physical fitness, fatigue, and chemotherapy completion rates: results of the PACES randomized clinical trial. J Clin Oncol. 2015;33(17):1918-27.

5. Kampshoff CS, Chinapaw MJ, Brug J, Twisk JW, Schep G, Nijziel MR, et al. Randomized controlled trial of the effects of high intensity and low-to-moderate intensity exercise on physical fitness and fatigue in cancer survivors: results of the Resistance and Endurance exercise After ChemoTherapy (REACT) study. BMC Med. 2015;13:275.

6. Schmitz KH, Courneya KS, Matthews C, Demark-Wahnefried W, Galvao DA, Pinto BM, et al. American College of Sports Medicine roundtable on exercise guidelines for cancer survivors. Med Sci Sports Exerc. 2010;42(7):1409-26.

7. McNeely ML, Campbell KL, Rowe BH, Klassen TP, Mackey JR, Courneya KS. Effects of exercise on breast cancer patients and survivors: a systematic review and meta-analysis. CMAJ. 2006;175(1):34-41.

8. Schwartz AL, Mori M, Gao R, Nail LM, King ME. Exercise reduces daily fatigue in women with breast cancer receiving chemotherapy. Med Sci Sports Exerc. 2001;33(5):718-23.

9. Schwartz AL. Fatigue mediates the effects of exercise on quality of life. Qual Life Res. 1999;8(6):529-38.

10. Schwartz AL. Daily fatigue patterns and effect of exercise in women with breast cancer. Cancer Pract. 2000;8(1):16-24.
11. Kolden GG, Strauman TJ, Ward A, Kuta J, Woods TE, Schneider $\mathrm{KL}$, et al. A pilot study of group exercise training (GET) for women with primary breast cancer: feasibility and health benefits. Psychooncology. 2002;11(5):447-56.

12. Dimeo F, Stieglitz RD, Novelli-Fischer U, Fetscher S, Mertelsmann R, Keul J. Correlation between physical performance and fatigue in cancer patients. Ann Oncol. 1997;8(12): 1251-5.

13. Winningham ML. Strategies for managing cancer-related fatigue syndrome: a rehabilitation approach. Cancer. 2001;92(4 Suppl): 988-97.

14. National Comprehensive Cancer Network: Cancer-related fatigue. Clinical practice guidelines in oncology. J Natl Compr Cancer Netw. 2003;1(3):308-31.

15. Dimeo FC. Effects of exercise on cancer-related fatigue. Cancer. 2001;92(6 Suppl):1689-93.

16. Knols R, Aaronson NK, Uebelhart D, Fransen J, Aufdemkampe G. Physical exercise in cancer patients during and after medical treatment: a systematic review of randomized and controlled clinical trials. J Clin Oncol. 2005;23(16):3830-42.

17. Courneya KS, Karvinen KH, McNeely ML, Campbell KL, Brar S, Woolcott CG, et al. Predictors of adherence to supervised and unsupervised exercise in the Alberta Physical Activity and Breast Cancer Prevention Trial. J Phys Act Health. 2012;9(6): 857-66.

18. Courneya KS. Exercise in cancer survivors: an overview of research. Med Sci Sports Exerc. 2003;35(11):1846-52.

19. Young-McCaughan S, Sexton DL. A retrospective investigation of the relationship between aerobic exercise and quality of life in women with breast cancer. Oncol Nurs Forum. 1991;18(4):751-7.

20. Courneya KS, Friedenreich CM. Relationship between exercise pattern across the cancer experience and current quality of life in colorectal cancer survivors. J Altern Complement Med. 1997;3(3):215-26

21. Galvao DA, Newton RU. Review of exercise intervention studies in cancer patients. J Clin Oncol. 2005;23(4):899-909.

22. van der Poel MW, Oerlemans S, Schouten HC, Mols F, Pruijt JF, Maas $\mathrm{H}$, et al. Quality of life more impaired in younger than in older diffuse large B cell lymphoma survivors compared to a normative population: a study from the population-based PROFILES registry. Ann Hematol. 2014;93(5):811-9.

23. van der Poel MW, Oerlemans S, Schouten HC, van de Poll-Franse LV. Elderly multiple myeloma patients experience less deterioration in health-related quality of life than younger patients compared to a normative population: a study from the populationbased PROFILES registry. Ann Hematol. 2015;94(4):651-61.

24. Husebo AM, Karlsen B, Allan H, Soreide JA, Bru E. Factors perceived to influence exercise adherence in women with breast cancer participating in an exercise programme during adjuvant chemotherapy: a focus group study. J Clin Nurs. 2015;24(3-4): 500-10.

25. Brunet J, Taran S, Burke S, Sabiston CM. A qualitative exploration of barriers and motivators to physical activity participation in women treated for breast cancer. Disabil Rehabil. 2013;35(24): 2038-45.

26. Lee IM, Shiroma EJ, Lobelo F, Puska P, Blair SN, Katzmarzyk PT. Lancet Physical Activity Series Working G: Effect of physical inactivity on major non-communicable diseases worldwide: an analysis of burden of disease and life expectancy. Lancet. 2012;380(9838):219-29.

27. Midtgaard J, Baadsgaard MT, Moller T, Rasmussen B, Quist M, Andersen C, et al. Self-reported physical activity behaviour; exercise motivation and information among Danish adult cancer pa- 
tients undergoing chemotherapy. Eur J Oncol Nurs. 2009;13(2): 116-21.

28. Littman AJ, Tang MT, Rossing MA. Longitudinal study of recreational physical activity in breast cancer survivors. J Cancer Surviv. 2010;4(2):119-27.

29. van den Berg JP, Velthuis MJ, Gijsen BC, Lindeman E, van der Pol MA. Hillen HF: [Guideline "Cancer rehabilitation"]. Ned Tijdschr Geneeskd. 2011;155(51):A4104.

30. (NCCO) NCCO: Cancer surivorship care; Cancer clinical practice guidelines. In.; 2018.

31. Runowicz CD, Leach CR, Henry NL, Henry KS, Mackey HT, Cowens-Alvarado RL, et al. American Cancer Society/American Society of Clinical Oncology Breast Cancer Survivorship Care Guideline. J Clin Oncol. 2016;34(6):611-35.

32. Resnick MJ, Lacchetti C, Penson DF. Prostate cancer survivorship care guidelines: American Society of Clinical Oncology practice guideline endorsement. J Oncol Pract. 2015;11(3):e445-9.

33. El-Shami K, Oeffinger KC, Erb NL, Willis A, Bretsch JK, PrattChapman ML, et al. American Cancer Society Colorectal Cancer Survivorship Care Guidelines. CA Cancer J Clin. 2015;65(6): 428-55.

34. Rock CL, Doyle C, Demark-Wahnefried W, Meyerhardt J, Courneya KS, Schwartz AL, et al. Nutrition and physical activity guidelines for cancer survivors. CA Cancer J Clin. 2012;62(4): 243-74.

35. Stout NL, Silver JK, Raj VS, Rowland J, Gerber L, Cheville A, et al. Toward a national initiative in cancer rhabilitation: recommendations from a subject matter expert group. Arch Phys Med Rehabil. 2016;97(11):2006-15.

36. NHS: Innovation to implementation: stratified pathways of care for people living with or beyond cancer. A 'how to guide'. In.; 2016.

37. Wiedenbein L, Kristiansen M, Adamsen L, Hjort D, Hendriksen C. Assessment of rehabilitation needs in colorectal cancer treatment: results from a mixed audit and qualitative study in Denmark. Acta Oncol. 2016;55(6):705-11.

38. Tvede CF, Brandstrup B, Engholm G. Tonnesen H: [Potential number of rehabilitated cancer patients in Denmark - an estimate]. Ugeskr Laeger. 2003;165(2):123-8.

39. Thorsen L, Gjerset GM, Loge JH, Kiserud CE, Skovlund E, Flotten T, et al. Cancer patients' needs for rehabilitation services. Acta Oncol. 2011;50(2):212-22.

40. Holm LV, Hansen DG, Johansen C, Vedsted P, Larsen PV, Kragstrup J, et al. Participation in cancer rehabilitation and unmet needs: a population-based cohort study. Support Care Cancer. 2012;20(11):2913-24.

41. Stevinson C, Fox KR. Feasibility of an exercise rehabilitation programme for cancer patients. Eur J Cancer Care (Engl). 2006;15(4):386-96.

42. Courneya KS, Mackey JR, Bell GJ, Jones LW, Field CJ, Fairey AS. Randomized controlled trial of exercise training in postmenopausal breast cancer survivors: cardiopulmonary and quality of life outcomes. J Clin Oncol. 2003;21(9):1660-8.

43. Segal R, Evans W, Johnson D, Smith J, Colletta S, Gayton J, et al. Structured exercise improves physical functioning in women with stages I and II breast cancer: results of a randomized controlled trial. J Clin Oncol. 2001;19(3):657-65.

44. Segal RJ, Reid RD, Courneya KS, Malone SC, Parliament MB, Scott CG, et al. Resistance exercise in men receiving androgen deprivation therapy for prostate cancer. J Clin Oncol. 2003;21(9): 1653-9.
45. Canestraro A, Nakhle A, Stack M, Strong K, Wright A, Beauchamp M, et al. Oncology rehabilitation provision and practice patterns across Canada. Physiother Can. 2013;65(1):94-102.

46. Santa Mina D, Alibhai SM, Matthew AG, Guglietti CL, Steele J, Trachtenberg J, et al. Exercise in clinical cancer care: a call to action and program development description. Curr Oncol. 2012;19(3):e136-44.

47. Ezendam N, de Ligt K, Oerlemans S, Velthuis M. Kankerzorg in beeld, over leven met en na kanker, IKNL \& NFK. 2019.

48. Segal R, Evans W, Johnson D, Smith J, Colletta SP, Corsini L, et al. Oncology rehabilitation program at the Ottawa Regional Cancer Centre: program description. CMAJ. 1999;161(3):282-5.

49. Demark-Wahnefried W. Print-to-practice: designing tailored print materials to improve cancer survivors' dietary and exercise practices in the FRESH START trial. Nutr Today. 2007;42(3):131-8.

50. Grabois M. Integrating cancer rehabilitation into medical care at a cancer hospital. Cancer. 2001;92(4 Suppl):1055-7.

51. Schmidt KD. Cancer rehabilitation services in a tertiary care center. Cancer. 2001;92(4 Suppl):1053-4.

52. Grol R. Personal paper. Beliefs and evidence in changing clinical practice. BMJ. 1997;315(7105):418-21.

53. IJsbrandy C, Ottevanger PB, Tsekou Diogeni M, Gerritsen WR, van Harten WH, Hermens RPMG: Review: effectiveness of implementation strategies to increase physical activity uptake during and after cancer treatment. Critical Reviews in Oncology $/$ Hematology 2017.

54. Fonhus MS, Dalsbo TK, Johansen M, Fretheim A, Skirbekk H, Flottorp SA. Patient-mediated interventions to improve professional practice. Cochrane Database Syst Rev. 2018;9:CD012472.

55. Kenealy T, Arroll B, Petrie KJ. Patients and computers as reminders to screen for diabetes in family practice. Randomizedcontrolled trial J Gen Intern Med. 2005;20(10):916-21.

56. Lund ML, Tamm M. Br nholm IB: Patients' perceptions of their participation in rehabilitation planning and professionals' view of their strategies to encourage it. Occup Ther Int. 2001;8(3):151-67.

57. Melander Wikman A, Fältholm Y. Patient empowerment in rehabilitation:"somebody told me to get rehabilitated". Adv Physiother. 2006;8(1):23-32.

58. Gagliardi AR, Legare F, Brouwers MC, Webster F, Badley E, Straus S. Patient-mediated knowledge translation (PKT) interventions for clinical encounters: a systematic review. Implement Sci. 2016;11:26.

59. Vallance JK, Courneya KS, Plotnikoff RC, Yasui Y, Mackey JR. Randomized controlled trial of the effects of print materials and step pedometers on physical activity and quality of life in breast cancer survivors. J Clin Oncol. 2007;25(17):2352-9.

60. Jacobson TA, Thomas DM, Morton FJ, Offutt G, Shevlin J, Ray S. Use of a low-literacy patient education tool to enhance pneumococcal vaccination rates. A randomized controlled trial. JAMA. 1999;282(7):646-50.

61. Mouland G. A letter to benzodiazepine users - an efficient way to reduce the prescription. Tidsskr Nor Laegeforen. 1997;117(21): 3097-100.

62. Thomas DM, Ray SM, Morton FJ, Drew JS, Offutt G, Whitney $\mathrm{CG}$, et al. Patient education strategies to improve pneumococcal vaccination rates: randomized trial. J Investig Med. 2003;51(3): $141-8$.

63. Kravitz RL, Epstein RM, Feldman MD, Franz CE, Azari R, Wilkes MS, et al. Influence of patients' requests for direct-toconsumer advertised antidepressants: a randomized controlled trial. JAMA. 2005;293(16):1995-2002. 
64. Khan MA, Shah S, Grudzien A, Onyejekwe N, Banskota P, Karim $\mathrm{S}$, et al. A diabetes education multimedia program in the waiting room setting. Diabetes Ther. 2011;2(3):178-88.

65. Miaskowski C, Dodd M, West C, Schumacher K, Paul SM, Tripathy D, et al. Randomized clinical trial of the effectiveness of a self-care intervention to improve cancer pain management. J Clin Oncol. 2004;22(9):1713-20.

66. Rabin C, Dunsiger S, Ness KK, Marcus BH. Internet-based physical activity intervention targeting young adult cancer survivors. Journal of adolescent and young adult oncology. 2011;1(4):18894.

67. Kroenke K, Taylor-Vaisey A, Dietrich AJ, Oxman TE. Interventions to improve provider diagnosis and treatment of mental disorders in primary care. A critical review of the literature. Psychosomatics. 2000;41(1):39-52.

68. Wensing M, Bosch M, Grol R. Developing and selecting interventions for translating knowledge to action. CMAJ. 2010;182(2): E85-8.

69. Grol R, Wensing M. What drives change? Barriers to and incentives for achieving evidence-based practice. Med J Aust. 2004;180(6 Suppl):S57-60.

70. Baker R, Camosso-Stefinovic J, Gillies C, Shaw EJ, Cheater F, Flottorp S, Robertson N: Tailored interventions to overcome identified barriers to change: effects on professional practice and health care outcomes. Cochrane Database Syst Rev 2010;(3):Cd005470.

71. IJsbrandy C, Ottevanger PB, Groen WG, Gerritsen WR, van Harten WH, Hermens RPMG. Study protocol: an evaluation of the effectiveness, experiences and costs of a patient-directed strategy compared with a multi-faceted strategy to implement physical cancer rehabilitation programmes for cancer survivors in a European healthcare system; a controlled before and after study. Implement Sci. 2015;10:128.

72. Grol R, Wensing M, Eccles M: Improving patient care: the implementation of change in clinical practice. 2005.

73. IJsbrandy C, Ottevanger PB, Gerritsen WR, van Harten WH, Hermens RPMG. Determinants of adherence to physical cancer rehabilitation guidelines among cancer patients and cancer centers: a cross-sectional observational study. J Cancer Surviv. 2021;15(1):163-77.

74. IJsbrandy C, Hermens RPMG, Boerboom LWM, Gerritsen WR, van Harten WH, Ottevanger PB. Implementing physical activity programs for patients with cancer in current practice: patients' experienced barriers and facilitators. J Cancer Surviv. 2019;13(5):703-12.

75. IJsbrandy C, van Harten WH, Gerritsen WR, Hermens RPMG, Ottevanger PB. Healthcare professionals' perspectives of barriers and facilitators in implementing physical activity programmes delivered to cancer survivors in a shared-care model: a qualitative study. Support Care Cancer. 2020;28(7):3429-40.

76. Grimshaw JM, Thomas RE, MacLennan G, Fraser C, Ramsay $\mathrm{CR}$, Vale L, et al. Effectiveness and efficiency of guideline dissemination and implementation strategies. Health Technol Assess. 2004;8(6):iii-v 1-72.

77. Prior M, Guerin M, Grimmer-Somers K. The effectiveness of clinical guideline implementation strategies - a synthesis of systematic review findings. J Eval Clin Pract. 2008;14(5):888-97.

78. Grol R: Improving patient care: the implementation of change in health care 2013.

79. Wensing M, Wollersheim H, Grol R. Organizational interventions to implement improvements in patient care: a structured review of reviews. Implement Sci. 2006;1:2.
80. Grol R, Grimshaw J. From best evidence to best practice: effective implementation of change in patients' care. Lancet. 2003;362(9391):1225-30.

81. Hopman P, Gijsen B, Brink M, Rijken M: Zorg- en leefsituatie van mensen met kanker 2012. Deelrapportage I: Ervaringen met ziekenhuiszorg. In.: NIVEL; 2012. https://nivel.nl/sites/default/ files/bestanden/DeelrapportI-Ervaringen-met-ziekenhuiszorg.pdf.

82. Booij JC, Zegers M, Evers PM, Hendriks M, Delnoij DM, Rademakers JJ. Improving cancer patient care: development of a generic cancer consumer quality index questionnaire for cancer patients. BMC Cancer. 2013;13:203.

83. May AM, Bosch MJ, Velthuis MJ, van der Wall E, Steins Bisschop CN, Los M, et al. Cost-effectiveness analysis of an 18week exercise programme for patients with breast and colon cancer undergoing adjuvant chemotherapy: the randomised PACT study. BMJ Open. 2017;7(3):e012187.

84. Medisch specialistische revalidatie bij oncologie Landelijke richtlijn, Versie: 2.0. In., 2.0 edn: Integraal kankercentrum Nederland (IKNL); 2018.

85. Cancer survivorship care Nation-wide guideline, Version: 1.0. In Edited by Nederland Ik, 1.0 edn; 2011.

86. Hermens RP, Ouwens MM, Vonk-Okhuijsen SY, van der Wel Y, Tjan-Heijnen VC, van den Broek LD, et al. Development of quality indicators for diagnosis and treatment of patients with nonsmall cell lung cancer: a first step toward implementing a multidisciplinary, evidence-based guideline. Lung Cancer. 2006;54(1): 117-24.

87. Mourad SM, Hermens RP, Nelen WL, Braat DD, Grol RP, Kremer JA. Guideline-based development of quality indicators for subfertility care. Hum Reprod. 2007;22(10):2665-72.

88. Tuinman MA, Gazendam-Donofrio SM, Hoekstra-Weebers JE. Screening and referral for psychosocial distress in oncologic practice: use of the distress thermometer. Cancer. 2008;113(4):870-8.

89. Holland JC, Bultz BD. The NCCN guideline for distress management: a case for making distress the sixth vital sign. J Natl Compr Cancer Netw. 2007;5(1):3-7.

90. Aaronson NK, Ahmedzai S, Bergman B, Bullinger M, Cull A, Duez NJ, et al. The European Organization for Research and Treatment of Cancer QLQ-C30: a quality-of-life instrument for use in international clinical trials in oncology. J Natl Cancer Inst. 1993;85(5):365-76.

91. Giesinger JM, Kieffer JM, Fayers PM, Groenvold M, Petersen MA, Scott NW, et al. Replication and validation of higher order models demonstrated that a summary score for the EORTC QLQC30 is robust. J Clin Epidemiol. 2016;69:79-88.

92. Smets EM, Garssen B, Cull A, de Haes JC. Application of the multidimensional fatigue inventory (MFI-20) in cancer patients receiving radiotherapy. $\mathrm{Br} \mathrm{J}$ Cancer. 1996;73(2):241-5.

93. Smets EM, Garssen B, Bonke B, De Haes JC. The Multidimensional Fatigue Inventory (MFI) psychometric qualities of an instrument to assess fatigue. J Psychosom Res. 1995;39(3):315-25.

94. Hibbard JH, Stockard J, Mahoney ER, Tusler M. Development of the Patient Activation Measure (PAM): conceptualizing and measuring activation in patients and consumers. Health Serv Res. 2004;39(4 Pt 1):1005-26.

95. Hibbard JH, Mahoney ER, Stockard J, Tusler M. Development and testing of a short form of the patient activation measure. Health Serv Res. 2005;40(6 Pt 1):1918-30.

96. Proctor E, Silmere H, Raghavan R, Hovmand P, Aarons G, Bunger A, et al. Outcomes for implementation research: conceptual distinctions, measurement challenges, and research agenda. Admin Pol Ment Health. 2011;38(2):65-76. 
97. Boyes AW, Clinton-McHarg T, Waller AE, Steele A, D'Este CA, Sanson-Fisher RW. Prevalence and correlates of the unmet supportive care needs of individuals diagnosed with a haematological malignancy. Acta Oncol. 2015;54(4):507-14.

98. Boyes AW, Girgis A, D'Este C, Zucca AC. Prevalence and correlates of cancer survivors' supportive care needs 6 months after diagnosis: a population-based cross-sectional study. BMC Cancer. 2012;12:150.

99. Holm LV, Hansen DG, Larsen PV, Johansen C, Vedsted P, Bergholdt $\mathrm{SH}$, et al. Social inequality in cancer rehabilitation: a population-based cohort study. Acta Oncol. 2013;52(2):410-22.

100. Jansen F, van Uden-Kraan CF, van Zwieten V, Witte BI, Verdonck-de Leeuw IM. Cancer survivors' perceived need for supportive care and their attitude towards self-management and eHealth. Support Care Cancer. 2015;23(6):1679-88.

101. Wang L, Dong J, Gan HB, Wang T. Empowerment of patients in the process of rehabilitation. Peritoneal dialysis international : journal of the International Society for Peritoneal Dialysis. 2007;27(Suppl 2):S32-4.

102. Richardson A, Storr J. Patient safety: a literature [corrected] review on the impact of nursing empowerment, leadership and collaboration. Int Nurs Rev. 2010;57(1):12-21.

103. Wijma AJ, Bletterman AN, Clark JR, Vervoort S, Beetsma A, Keizer D, et al. Patient-centeredness in physiotherapy: what does it entail? A systematic review of qualitative studies. Physiother Theory Pract. 2017;33(11):825-40.

104. Hope A. A survivor's perspective on the power of exercise following a cancer diagnosis. Clin J Oncol Nurs. 2016;20(6 Suppl):S31-2.

105. Kuijpers W, Groen WG, Aaronson NK, van Harten WH. A systematic review of web-based interventions for patient empowerment and physical activity in chronic diseases: relevance for cancer survivors. J Med Internet Res. 2013;15(2):e37.

106. Reb A, Ruel N, Fakih M, Lai L, Salgia R, Ferrell B, et al. Empowering survivors after colorectal and lung cancer treatment: pilot study of a self-management survivorship care planning intervention. Eur J Oncol Nurs. 2017;29:125-34.

107. Campbell MK, Fayers PM, Grimshaw JM. Determinants of the intracluster correlation coefficient in cluster randomized trials: the case of implementation research. Clin Trials. 2005;2(2):99-107.

108. Schulz KF, Grimes DA. Generation of allocation sequences in randomised trials: chance, not choice. Lancet. 2002;359(9305): $515-9$.

Publisher's note Springer Nature remains neutral with regard to jurisdictional claims in published maps and institutional affiliations. 